\title{
A RAZÃO INVERTIDA: O TECNICISMO NA EDUCAÇÃO COMO VEÍCULO DE COLONIZAÇÃO DO MUNDO VIVIDO
}

Edna Gusmão de Góes Brennand ${ }^{1}$ Universidade Federal da Paraíba - UFPB ednabrennand@gmail.com

\author{
José Washington de Morais Medeiros ${ }^{2}$ \\ Instituto Federal de Educação, Ciência e Tecnologia da Paraíba - IFPB \\ washi_med@yahoo.com.br
}

\begin{abstract}
Resumo
Subsidiado pelo conceito de racionalidade instrumental, o texto discute sobre a razão técnica e seu uso na educação, destacando como o tecnicismo fortalece as estratégias de colonização do mundo da vida da escola. Reflete sobre como a pedagogia tecnicista corrobora uma educação atrelada muito mais às ciências tecnoempiristas do que histórico-hermenêuticas. Metodologicamente, busca categorias habermasianas, como racionalidade, linguagem, mundo vivido, mundo sistêmico e patologias sociais, para estabelecer os liames entre razão técnica e educação. Sintetiza os benefícios que a colonização do mundo vivido traz ao mundo sistêmico, proporcionando ao Estado mais poder em sua governança político-econômica, livrando-o de pressões e de reivindicações por parte de extratos sociais. A ideia de desenvolvimento, como matriz funcional do fortalecimento dos sistemas, é confundida com o desenvolvimento da competência individual, o que torna o sujeito muito mais um agente reprodutor das diretrizes normativas da cultura invadida do que um agente do agir comunicativo.
\end{abstract}

Palavras-chave: razão técnica. tecnicismo e educação. mundo sistêmico. mundo vivido.

\section{INVERTED REASONING: TECHNICISM IN EDUCATION AS A MEANS OF COLONIZATION IN THE NATURAL WORLD}

\begin{abstract}
Supported by instrumental rationality, this study addresses technical reason and its use in education. The aim is to show how technicism strengthens lifeworld colonization strategies, through school. Reflections on how technicist pedagogy collaborates with education associated mostly with techno-empiricist rather than historichermeneutic sciences. Methodologically the study pursues habermasian categories, such as rationality, language, lifeworld, systemic world, social pathologies, to establish ties between technical reason and education. A synthesis of the benefits that lifeworld colonization brings to the systemic world, providing more power to the State's governing politics and economy, relieving the pressure and claims of social groups, is presented. The idea of development as the functional matrix of the strengthening of systems, is confused with the development of individual competence, turning the subject more often the reproducing agent of policy guidelines of the invaded culture, than the agent of communicative action.
\end{abstract}

Key-words: technical reason. technicism and education. systemic world. lifeworld.

\footnotetext{
${ }^{1}$ Doutora em Sociologia. Professora do Programa de Pós-Graduação Gestão em Organizações Aprendentes (PPGOA), do Programa de Pós-Graduação em Educação (PPGE), e Pesquisadora do Laboratório de Vídeo Digital (LAVID), da Universidade Federal da Paraíba - UFPB.

${ }^{2}$ Doutor em Educação. Professor do Mestrado Profissional em Educação Profissional e Tecnológica (ProfEPT) do Instituto Federal de Educação, Ciência e Tecnologia da Paraíba - IFPB. Professor colaborador do Programa de Pós-Graduação Gestão em Organizações Aprendentes (PPGOA) - UFPB.
} 


\section{INTRODUÇÃO}

Na tentativa de perceber como a educação é invadida por forças que se põem contrárias ao seu projeto moderno de mundo, este texto foi escrito com a finalidade de refletir sobre como o tecnicismo fortalece as estratégias da colonização da escola. Considerando que a pedagogia tecnicista corrobora uma educação atrelada muito mais às ciências tecnoempiristas do que histórico-hermenêuticas, a perspectiva de nossa discussão parte do pensamento de que a pedagogia tecnicista ajuda a legitimar a colonização do mundo vivido.

Habermas (2001) utiliza o conceito de colonização como um processo macroestrutural que reúne um conjunto de ações sobrepostas pelo mundo sistêmico (MS) no mundo vivido (MV). A colonização é uma invasão nas estruturas culturais, sociais e cognitivas, que desfavorece o acervo natural de saberes do sujeito e, ao mesmo tempo, imprime-lhe conteúdos ideológicos que guardam a manutenção da ordem colonizadora. Nesse prisma, as investidas de intervenção sistematicamente ideológicas desarmonizam a independência e o equilíbrio entre MV e MS, notadamente as duas grandes esferas constituintes da sociedade.

Do sucesso da colonização sobre as estruturas do mundo vivido, surgem as patologias sociais, que são distúrbios de ordem prática, amplamente tributárias da ideia de liberdade e de igualdade, que culminam em sérios desajustes, como a violência que se firma como artífice do (des)entendimento entre os sujeitos. O texto discute que, na escola, as patologias desenrolamse: a) como consequência do racionalismo aplicado; b) a partir da violência simbólica como mecanismo da autoridade pedagógica sobre a aprendizagem; c) por intermédio da obstrução na produção de saberes e racionalização da cultura; e d) por meio da educação como valor de mercado.

Em razão disso, pretendemos esclarecer como a rede integradora da ordem política do mundo dos sistemas tenta esmorecer a utopia emancipatória da educação, por intermédio das desarticulações estruturais que impedem que a escola reproduza racionalmente (simbólica e material) o mundo vivido. Nosso intuito é de situar o leitor nas tramas entrelaçadas que utilizam do mesmo método: ações dirigidas a fins (racionalidade instrumental), para encadear as raízes do tecnicismo nas práticas educativas.

Subsidiados pelo conceito de racionalidade instrumental, podemos inferir que a razão técnica é resultante do emprego monológico do saber proposicional. Esse tipo de saber não é condizente com aprendizagens processuais, isto é, abertas ao questionamento sobre a construção do conhecimento e o conteúdo de suas verdades. Em que pese tudo isso, a 
racionalidade instrumental do tecnicismo enraíza, nas esferas do mundo vivido escolar (agentes educativos, valores pedagógicos e organização social), manifestações multiplicadoras de interesses próprios, que geram a arquitetura de um conjunto de poder pautado nas conjecturas sistêmicas de um mundo autorreferencial.

Advindo de vertentes teóricas relacionadas ao Behaviorismo e ramificadas nos trabalhos dos americanos Burrhus Frederick Skinner, Benjamin Bloom e Ralph Tyler, o tecnicismo surgiu do modelo de produção e das práticas tayloristas de eficiência social, traduziu-se na ideologia tecnocrática do comportamento e das políticas educacionais e tomou a cena nos espaços de ação social no Século XX (GOODSON, 2003). Funcional em sua essência, evidencia-se como uma das sínteses configurativas da racionalidade instrumental na educação. Autorreferenciada por um sentido exacerbado de "prático" em sua conduta, a razão técnica propôs a "juntada" de que tanto o racionalismo ocidental necessitava, no sentido de fazer dominar o agir econômico sobre outras manifestações da vontade individual, da opinião coletiva, do direito, da moralidade e da comunicação. Suas ideias sustentam a integração da competência humana em sociedade e associa-se muito mais ao sentido de se adaptar aos mecanismos de produção, estabelecendo-se como "centro", através do qual flui e conflui toda a dinâmica da ordem estabelecida pelo dinheiro e homologada pelo poder, conforme veremos a seguir.

\section{RAZÃO TÉCNICA E EDUCAÇÃO}

Inspiradas na eficiência do processo educativo como parte da produtividade dos papéis individuais perante o agir social (princípios da racionalidade meios/fins), as manifestações da racionalidade instrumental alojaram na educação uma forma de razão fundada na técnica e em seus parâmetros de desenvolvimento social. No campo da educação, tal razão se situou como corrente ou tendência referida pela pedagogia tecnicista, e esse modelo pedagógico se tornou um paradigma educacional de profunda relevância para o desenvolvimento de propósitos de utilidade sobre os saberes, atrelando a importância do conhecimento na mesma proporção em que induz a torná-lo "útil”" (uso de coisas práticas). O vínculo entre a natureza do conhecimento e a rede de relações com outros objetos é feito com uma ação condutora que define o ideal de "homem" e de "sociedade" como mecanismos produtivos de influências recíprocas.

Essas características (produtividade/utilidade), eminentemente vinculadas à instrumentalização da razão como mecanismo de "retidão" das ações sobre o conhecimento, 
corroboram a supremacia do neopragmatismo na educação: um desdobramento positivista que se vale do cientificismo para coordenar o conhecimento com a rigorosidade de princípios estabelecidos por suas próprias leis. Por essas vias, encarada como subsistema elementar, a educação deve ajustar-se ao intuito que lhe cabe, no sentido de buscar a hegemonia do sistema de que faz parte. Com apelos metodológico-funcionais em sua essência e respaldado na filosofia neopositivista, de modelo neopragmático, o tecnicismo propõe uma "engenharia do conhecimento" baseada na propulsão de comportamentos ajustados aos papéis sociais que lhe foram pré-estabelecidos, o que significa dizer que a gestão do "fazer" é o preceito normativo mais relevante para a pedagogia e, consequentemente, para a aprendizagem.

Percebida como fonte de captação e de capacitação da atividade do "fazer", a educação deve promover os recursos intelectivos a fim conduzir, com dedicação, presteza e responsabilidade as leis da produção. Nessas vias, o currículo escolar é o modelo-guia do qual saem os ensinamentos eficazes para absorver o mercado, isto é, o saber valorativo para a progressão profissional. Desse modo, a finalidade utilitarista do conhecimento, a ação pragmática sobre a realidade e a condução (reducionista) da ciência para conseguir resultados concretos, com o fim de efetivar a dinâmica do desenvolvimento (enfraquecimento do mundo vivido), corporificam os “organismos vivos" interpolados no seio do tecnicismo.

De acordo com Habermas (1980), o utilitarismo do conhecimento não dá espaços para que argumentos substanciais (pretensão de validade do discurso), construídos através de interferências lógicas por parte do aluno, sejam levantados para questionar os fundamentos desse próprio conhecimento no processo de ensino-aprendizagem. Para concretizar a ideia colonizadora, argumentos substanciais podem ser intervenções no sucesso instrumental e, por isso, são "males" que devem ser cortados pela raiz, uma vez que se tornam perigosos tanto para legitimar as normas recomendadas pela ideologia do currículo escolar, quanto para a demanda de quem precisa do conhecimento como legitimação formal da competência.

A plataforma de ação do tecnicismo, altamente regida pela racionalidade meio/fins, é quase autoimune a qualquer "estranheza" que se aventure a lhe causar desarmonias, o que significa dizer que interesses constitutivos do conhecimento voltados para a evolução da subjetividade (validade racional da moral) não conseguem vislumbrar os horizontes formadores de argumentos substanciais e, com eles, de processos educativos como processos emancipatórios.

O caráter objetivo da educação tecnicista planifica o processo de ensino, com o fim de potencializar a organização racional do saber para que não haja interferências subjetivas, o que 
minimiza os "perigos" de sua eficiência. A mecanização do processo averba, assim, a segurança de que os objetivos planejados terão o êxito esperado pelo sistema condutor. A programação do ensino visa firmar o resultado da aprendizagem esperada, posto que os recursos didáticometodológicos, esboçados como manual operacional que objetivam concretizar a transferência de conteúdos, arquitetam-se de acordo com as pretensões de cada disciplina e sua intervenção nas crises que ameaçam o bom funcionamento dos papéis sociais.

Relacionada a isso, a escola, transformada em um "pequeno mundo prático", exerce suas funções de estabelecer os conteúdos eficazes para coligar as capacidades humanas de aprender às agilidades das ações sociais dirigidas. Nesse sentido, a organização da experiência se autoevidencia como objetivo programado das etapas do ensino e da aprendizagem e passa a ser o lugar, por excelência, de todo o esforço individual, a fim de que o sujeito seja preparado para resolver os problemas práticos que aparecerem diante do cumprimento otimizado de suas tarefas profissionais.

Na unilateralidade desse caminho, a perspectiva da interdisciplinaridade não encontra muitas saídas em instituições escolares, cuja pedagogia disciplinar, verbalista e formalista não se ocupa de outra coisa, a não ser de fortalecer seus vínculos metafísicos, centralizados no ensino demonstrativo e regulador de uma aprendizagem normativamente enclausurada dentro de limites ideológicos.

\section{BASES DA PEDAGOGIA TECNICISTA}

Nessa mesma perspectiva de entendimento, Saviani (1983), enfatiza que a garantia de que o processo seja eficiente dá-se pela correção das deficiências docentes. Assim, a preocupação da pedagogia tecnicista "passa a ser a organização racional dos meios, enquadrando professor e aluno em uma posição secundária, relegados à condição de executores de um processo cuja concepção, planejamento, coordenação e controle ficam a cargo de especialistas [...] neutros, objetivos, imparciais" (SAVIANI, 1983, p. 6).

$\mathrm{Na}$ pedagogia tecnicista, quanto mais houver conteúdos curriculares e práticas educativas eficientes para formar pessoas condizentes com os padrões de produção, mais desenvolvida será a sociedade, e as ameaças contra a estabilidade do sistema diminuirão. Saviani (1983, p. 7) assevera que "[...] a pedagogia tecnicista acabou por aumentar o caos no campo educativo, gerando tal nível de descontinuidade, de heterogeneidade e de fragmentação que praticamente impediu o trabalho pedagógico". 
Escola e mundo da indústria estão entrelaçados na lógica do aluno-trabalhador, e o centro gravitacional da escola foca suas atenções na acepção de que o conhecimento só tem valor quando se converte na própria utilidade. Abstrações que fogem dessa regra devem ser banidas do currículo e, consequentemente, da ideia de uma aprendizagem reflexiva, haja vista que não servem a outros propósitos senão o de suas próprias "ridicularidades", sob a ótica do neopragmatismo.

Em decorrência disso, componentes do ensino (currículo, didática, aprendizagem e avaliação) assumem um tratamento que estrutura a força objetiva da verdade que lhe convém, por meio de propostas educativas e de planos curriculares cujas condições objetivas são determinadas pelos interesses, materiais ou simbólicos, de quem os gerou. O método de ensino corrobora a natureza do próprio conteúdo, um conjunto de sequências lógicas e psicológicas, elaborado a partir da ciência objetiva. Luckesi (1994, p. 61) enfatiza que a natureza da tendência tecnicista na educação tem três componentes básicos: "[...] a) o estabelecimento de comportamentos terminais, através de objetivos instrucionais; b) a análise da tarefa de aprendizagem, a fim de ordenar sequencialmente os passos da instrução; c) executar o programa, reforçando gradualmente as respostas corretas correspondentes aos objetivos”.

Assim posto, erigido pela dimensão instrumental da razão, o tecnicismo desatou os nós para enquadrar os sistemas econômicos e administrativos no interior do fenômeno humano gerador de sentidos reflexivos sobre a existência: o sistema de ensino, cujo eco de sua voz entoa nos redutos mais profundos da "vontade de vencer na vida", no "mito do meu filho doutor", na concepção de inteligência como capacidade da memória de estocar e transferir informações, como estratégia para ganhar cada vez mais dinheiro e fazer fortuna, dentre outros fatores. $\mathrm{O}$ lastro de sua ideia de progresso compõe desde propostas de associações comunitárias, cooperativismo, filantropismo e terceiro setor, até elaborados programas de governo e formação de blocos internacionais.

Os investimentos ideológicos com que a razão técnica condiciona o comportamento do indivíduo nas complexas sinergias da aprendizagem corroboram as ações do MS dirigidas aos fins de seus próprios sucessos. Em termos históricos, precisamente em relação à educação brasileira, poderíamos dizer que o tecnicismo assume uma conduta de valor quase incomensurável para a ideia de progresso social. Assim, é de supor que, à luz de Habermas $(2003 ; 2001 ; 1999 ; 1990)$, poderíamos dizer que essa corrente se lança como resultado efetivo do processo invasor da escola e, mais além, como um dos veículos da colonização social. 
Nesse ínterim, a tendência tecnicista firmou-se na educação brasileira a partir da ideia exacerbada de evolução civilizatória como desenvolvimento modernista. Em compasso com acontecimentos históricos de caráter totalitário, como a Ditadura Militar, a perspectiva tecnicista da educação encampou pedagogias geridas pelas manifestações da racionalidade instrumental nas políticas, nas práticas educativas e, não menos importante, na formação de professores: agentes em quem recaem as exigências e as responsabilidades de conduzir e de reproduzir a ideologia técnica através do ensino. A razão técnica tornou-se uma condição aparentemente cristalizada sobre a educação, principalmente considerando as dificuldades que os professores enfrentam para conduzir propostas pedagógicas alternativas.

Amparado pela capitalização do conhecimento incorporado pelo sujeito, o tecnicismo continua validando suas verdades sobre o mundo vivido do espaço escolar, conduzido pelas esteiras atuais da nova fase de modernização da sociedade informacional e global. Por esses meios, os desdobramentos que assumiu no terreno fecundo da educação brasileira fez prosperarem, justamente, os germes a que a reforma do ensino se propunha: o preparo para a produção industrial. A razão "encantada" pelos artifícios da reprodução do capital e, com ele, da reprodução da cultura, é conduzida a uma identidade particularmente fortuita, incisivamente inclinada a imperar somente seu lado desviante, como razão instrumental.

O desfalque nos ideais emancipatórios tem se traduzido como um grande fosso para a evolução coletiva do pensamento e das possibilidades do agir comunicativo. Habermas (2001, 1999) entende por emancipação o exercício cada vez mais valorativo, expressivo e expansivo dos atos comunicativos e suas complexidades (domínio da língua, participação interativa nos espaços de fala, nos processos argumentativos e na (re)avaliação das verdades). No entanto, é com base na informação, como linguagem, e na experiência, como aprendizado, que a pedagogia tecnicista substitui o primado comunicativo da reflexão argumentativa pelas informações linguísticas que adquirimos com o simples contato com algo no mundo. Isso inverte os interesses emancipatórios e altera o modo como a educação confirma, ao invés de transformar, a realidade por intermédio do progresso técnico sob as formas de capitalizar o conhecimento humano. 


\section{A TEORIA DO CAPITAL HUMANO COMO FUNDAMENTO DA PEDAGOGIA TECNICISTA}

$\mathrm{Na}$ educação brasileira, o tecnicismo mostra-se como uma face do capitalismo avançado, em que o sistema econômico rende forças ao controle do Estado. Nesse contexto, fornece uma espécie de "moldura cognitiva", idealizada pela programação do MS como estratégia da colonização cognitiva. Para consolidar a razão técnica como veículo eficaz do sucesso sistêmico sobre a educação, a "economia do conhecimento" dá subsídios até então praticamente desconsiderados pelos investimentos econômicos: o capital humano.

No dinâmico desenvolvimento civilizatório do Ocidente, a formação humana tem se constituído como algo que, em termos gerais, faz parte da teoria do investimento. A chegada da ideia de investimento na educação confirma ainda mais com as autoevidências do discurso prático e do pragmatismo do saber, isto é, propensão para valorizar a instrução. A linha de pensamento seguida pela economia da educação esforça-se para formar indícios que contribuam, em sua ótica oportunista, para aumentar os problemas enfrentados pela educação. Assim, com a pretensão de evidenciar o valor da educação, a Economia levantou teses e incorreu em fundamentos que subsidiaram propostas educacionais latentes. O valor econômico da educação foi obtido com a centralização do capital humano, um dos investimentos mais produtivos do capitalismo tardio.

A ideia consistia em visualizar as crises dos fatores essenciais da produção e, ao mesmo tempo, lançar as diretrizes para renovar as interfaces entre capital e trabalho, desgastadas pelas derrocadas do Marxismo, principalmente em sua fase socialista, de tomada do poder. Shultz (1967), um dos principais expoentes da teoria, defendia a tese de que o investimento básico no capital humano é a educação, que o trabalho depende não do capital material, mas do capital humano, e que "o valor econômico da educação depende, predominantemente, da procura e da oferta da instrução, considerada como um investimento" (SHULTZ,1967, p. 13).

Nesse aspecto, usufruindo das diferentes formações da teoria econômica, Shultz (1973) classificou atividades e componentes da Economia e teceu uma crítica à sua dimensão clássica: não era mais oportuna/adequada ao contexto dos investimentos da modernização econômica. Assim, Shultz (1973) classifica os componentes do capital humano como investimentos de base para a economia moderna: escolaridade de nível mais alto; treinamento realizado no local do emprego; migração; e saúde e informação econômica. A renovação no conceito de capital, que lhe atribui uma dimensão de sentido não materialista, fez tremerem as bases tanto da Economia 
quanto da Educação. As capacidades adquiridas pelos agentes humanos passaram a corresponder, a essa altura, a uma fonte de produtividade e renovaram o conceito clássico de investimento que amplia o conceito de capital.

Com a tese de que o pensamento econômico negligenciou os investimentos no homem e na pesquisa, Shultz (1967) enfatiza que o conceito de informação é uma estratégia importante do processo, baseado em duas vias: a) possibilita a transformação de novas capacidades técnicas que, quando transmitidas, são formas de capital humano; b) possibilita a transformação de novos materiais que, quando realizados, são novas formas de capital não humano. Considerando que o ensino e a aprendizagem são os fatores mais importantes da educação, a teoria shultziana passa a conceber que esses dois parâmetros são inter-relacionados em função do principal componente do capital humano: a instrução. Assim, na acepção de Shultz (1967, p. 18),

[...] educar significa, etimologicamente, revelar ou extrair de uma pessoa algo potencial e latente; significa aperfeiçoar uma pessoa, moral e mentalmente, de maneira a torná-la suscetível de escolhas individuais e sociais e capaz de agir em consonância; significa prepará-la para uma profissão, por meio de instrução sistemática [...].

Para o autor, a instrução surgiu como uma força de "extração", um componente final do processo educativo. "Instrução é assim um conceito aplicado aos serviços educacionais" (SHULTZ, 1967, p. 19). Foi assim que Schultz (1973) se empenhou em tornar adequado e prático aplicar o conceito de capital no humano. O homem, como "matéria-prima", e o conhecimento, como "motor" da produção, transformaram propostas pedagógicas em investimentos objetivos de reprodução e retorno da economia modernicista. Assim, o autor desconstruía o conceito tradicional de capital e insuflava sobre ele sua não homogeneidade, o que resultou no capital humano que, heterogêneo e dinâmico, assumia o caráter de produtor e de consumidor ao mesmo tempo.

Considerando que a educação é um conjunto organizado e especializado de atividades, cuja arena se centraliza na escola como instituição formalmente credenciada para legitimar o signo do sujeito voltado para as próprias tarefas, o autor parece dissociar a instrução como consumo da educação como processo de construção do conhecimento. Essa distinção, no entanto, é o prenúncio para o fato de que, de acordo com o autor, a própria Ciência também pode se comprometer com a produção do capital, até mesmo as chamadas ciências básicas e seus empenhos em propiciar as bases para concretizar as aplicações empíricas usadas com 
interesses práticos. A educação, como instrução, faz parte de um amplo processo cultural, cujo conceito inclui a produção e o consumo como atividades econômicas. Por essas vias, esse entendimento nos conduz, diante das teses de Shultz (1967), à seguinte questão: se, para o capital humano, um dos aspectos mais valorativos da educação é a instrução, qual o valor da instrução?

Poderíamos dizer que a instrução tem, grosso modo, um valor orientado para os fins do próprio intelecto, isto é, diz respeito ao bem-estar individualizado que requer investimento em uma atividade econômica autovalorativa, não necessariamente condizente com questões éticas e de benefício coletivo. A ideia da instrução não como uma despesa, per si, mas como uma satisfação agregada de valores associados traz para a educação consequências que podem ser imaginadas sem muita dificuldade. Rechaçada por infiltrações que realçam no indivíduo sensações de autoevolução do $e u$ (ontogênese), por meio do desenvolvimento coletivo (filogênese), a educação invertida é tomada como um jogo de imagens, cujas representações constroem sentidos equivocados sobre a formação humana e configuram lhe como arcabouço de liberdade, mas mantendo velado o mais absoluto controle. Para o indivíduo, a sensação é de escolhas, de caminhos que se abrem, de possibilidades. No entanto, o capital humano "esconde nas mangas" as "cartadas" do próprio tecnicismo, no sentido de privilegiar habilidades individuais mais precisas, tanto para a própria satisfação (utilização com interesses próprios já que aumenta os rendimentos pessoais), quanto para o aproveitamento econômico (utilização com interesses do capital, porquanto aumenta as chances de maximizar a produção).

O capital humano faz parte das atividades econômicas de investimento e ampara a formação humana como plataforma de interesses diretos para a economia da educação. Seus mecanismos, pautados na detenção do discurso prático e na valorização do acúmulo de saberes técnicos, esforçam-se para conferir à educação seu valor de uso. Dessa maneira, como os componentes da instrução (valores morais pré-estabelecidos, refinamento de gosto, padrões de comportamentos e da arte de viver) buscam sua valorização cada vez mais acentuada no terreno da condição humana em sociedade, podemos perceber os domínios dos propósitos da educação como elemento categórico dos imperativos sistêmicos. Nesse aspecto, os investimentos econômicos no conhecimento tutelam o desenvolvimento cognitivo como capital humano. Os processos educativos transformam o potencial de apreensão e construção do saber em mera introjeção de conteúdos, o que é chamado de evolução social. Nesse sistema de racionalização do saber em bases propositais, a instrução e a mercadoria assumem o mesmo valor de venda, mas com um grande diferencial: a instrução é, talvez, um dos maiores investimentos da história 
do capitalismo porque dela emergem e a ela convergem estratégias econômicas que fazem o capital render cada vez mais. Em outros termos, quanto mais instrução, mais mão de obra qualificada para o trabalho, mais produção, mais circulação de moeda, mais consumo e lucro. A instrução é a base do capital humano, que é o caminho mais produtivo para se reproduzirem a cultura enlaçada, a razão invertida, as crises, as contradições e as patologias sociais da escola e da sociedade, no limiar do capitalismo tardio ou liberal.

$\mathrm{O}$ arrefecimento sofrido pela ideia de liberdade, diante do cenário moderno da razão técnica, corresponde à disposição que o sujeito deve implementar para se adequar aos mecanismos da formação/qualificação voltada para gerir os interesses sistêmicos. Por essas vias, o domínio do pensamento técnico, para o capital humano, diz respeito a um tipo de liberdade que só pode ser exercido dentro de suas próprias dimensões. Citando William Faulkner, Shultz (1973, p. 52) enfatiza que "o homem sem capacidades técnicas e sem conhecimentos apoia-se terrificamente no nada". Nesse contexto, os fundamentos da educação foram intimados a alocar o caráter humanístico do desenvolvimento moral como personagem coadjuvante, quase imperceptível, diante da gestação de habilidades técnicas utilitárias, da hipervalorização do saber aplicado ao trabalho como proposta pedagógica do crescimento modernista, conforme enfatizam os laços estreitos entre técnica e capital.

$\mathrm{Na}$ formação de um mundo escolar como unidade de capital e como esfera do capitalismo cognitivo, fundado pela funcionalidade do ensino prático e pelo utilitarismo da aprendizagem como produto de valor mercadológico, a pedagogia tecnicista institui a verdade objetiva do conhecimento standard, por meio da teoria do capital humano como fundamento. O progresso técnico corrobora a propagação da educação como instrução, isto é, faz valer a elaboração do conhecimento, com o fim de gerir e inovar as perspectivas estratégicas das forças geradoras da condução social e, consequentemente, da integração dos sistemas.

\section{O RACIONALISMO APLICADO COMO FORMA DE LEGITIMAÇÃO DOS SISTEMAS NO ESPAÇO ESCOLAR}

O investimento feito por Habermas (2001) para discutir sobre o diagnóstico do nosso tempo também foi articulado com as constantes reconstruções que o autor faz, ao longo da Teoria da Ação Comunicativa, do pensamento weberiano. Um ponto importante a partir do qual conflui a concordância de Habermas com as teses de Weber corresponde ao diagnóstico 
da perda de sentido e da perda da liberdade, sofridas pela sociedade em decorrência da tecnificação e da burocratização da política.

Para Weber (2001; 2000), o Estado racional foi constituído no Ocidente, paramentado por um funcionamento jurídico que mantém a dominação como administração, rege as direções políticas e, ao mesmo tempo, é dirigida por ela. O processo histórico, político, social e cultural da racionalização galgou as formas constituintes dos direitos, do trabalho, da força produtiva e da organização política e partidária, mas, sobretudo, da burocratização, que passou a redefinir as relações sociais e econômicas.

As "perdas" da modernidade são, pois, consequências das formas de dominação fundadas em quadros administrativos estáveis, firmados para assegurar a organização e o funcionamento do Estado nas ações do indivíduo. O alto grau de racionalismo estrutural contribui para que haja uma sensação de "perdas", já que entroniza a razão e dela absorve as consequências que condensam a razão técnico-instrumental em favor do capital, cujo eixo de controle é a forte burocracia estatal, o que enquadra as formas de vida do homem moderno. Apesar de refletir sobre as interferências de uma base de racionalidade no tecido social, amplamente fortificada pelo poder, Habermas (2001) reconhece que Weber não foi capaz de apontar uma saída para o "caos racional" interposto pela assunção da racionalidade instrumental sobre as esferas de vida.

Considerando esses limites, o autor investe em uma compreensão dos subsistemas de ação racional, na perspectiva de reinterpretá-los, e encontra no modelo comunicativo uma via mais frutífera para entender o complexo processo de racionalização social, por intermédio das forças propulsoras que formam os subsistemas de ação econômicos e administrativos. Diferenciando-se desse patamar de racionalização, Habermas (2001) distingue duas pilastras, sobre as quais emergem sua nova teoria da sociedade e discute criticamente sobre as evidências e as distinções das duas vias de acesso à compreensão racional de mundo na contemporaneidade: o mundo sistêmico (MS) e o mundo vivido (MV).

Para o terreno da educação, a (re)interpretação que Habermas (2001) faz de Weber, notadamente em busca do equilíbrio racional dos dois palcos de mundo (MS e MV), propicianos compreender como muitos dos problemas da aprendizagem (distúrbios), da avaliação (repetência), da assiduidade (evasão), do currículo (conteúdos lineares), do conhecimento (reprodução), das relações interpessoais (individualismo), das hierarquias (poder), dentre outros, não são somente desajustes do mundo interno da educação. Nesse prisma, muitos dos problemas educacionais parecem fazer parte do atrelamento que o mundo sistêmico impõe à 
escola. O conceito habermasiano de mundo vivido nos dá subsídios para entendermos bem mais como o contexto do racionalismo aplicado apresenta-se como estratégia de domínios sobre a educação.

\section{OS FIOS (IN)VISÍVEIS DO MUNDO VIVIDO E DO MUNDO SISTÊMICO COMO TESSITURAS DE ATUAÇÃO DO TECNICISMO}

Para Habermas (2001), o mundo vivido, como parte bidimensional da sociedade, é, por excelência, o lugar dos processos comunicativos. Em sua natureza interior, a arquitetura das interações comunicativas possibilita a construção de uma jornada argumentativa que se valida pela naturalidade com que os sujeitos sociais buscam o consenso sobre as coisas. Por ser natural e espontâneo, mantém-se nas estruturas pré-reflexivas, com características não tematizadas e que não são postas em dúvida. As certezas firmadas permanecem não problematizadas até o momento em que entram na pauta das reflexões temáticas e perdem sua inquestionabilidade. Nessa perspectiva, quando os sujeitos sociais erguem discussões que refutam sua própria existência, o mundo vivido entra no debate, e suas estruturas naturais perdem um pouco sua naturalidade.

Trata-se de uma plataforma de ação inata, sobre a qual a identidade individual e a social se constituem. Portanto, o mundo vivido abrange a existência humana em seu modo latente, que é formada pela compreensão natural da vida, principalmente a partir do acervo de saberes organizados linguisticamente, que são específicos do grupo de pertença e transmitidos pela herança cultural das gerações. O mundo vivido é a instância intersubjetiva que se orienta pelo agir comunicativo no cotidiano e se reproduz a partir da crescente autonomia das esferas: a) pessoais (desenvolvimento cognitivo), b) culturais (reflexão e revalidação de valores) e c) sociais (construção de normas válidas) (HABERMAS, 2001).

A evolução desses três eixos fundamentais constitui a base de validade sobre a qual o mundo da vida se fortalece racionalmente. Em seu desenvolvimento, a comunicação linguística é o fenômeno de mais realce, voltada para o caráter referente e constituinte do cotidiano de sentidos, já que é por meio do compartilhar do entendimento que surge o consenso ideal para que o discurso coletivo construa as verdades refutáveis, aceitas por todos os participantes. Nesse grande celeiro cultural e linguístico, o desacordo não conduz necessariamente à indiferença, e os interesses particularizados não correspondem a conflitos que buscam dizimar a participação do outro na comunidade interativa. 
Valorativo em sua base integradora da ordem democrática da comunicação, o mundo vivido é sempre intersubjetivo e integra a constituição das coisas no mundo com intercompreensões para situar problemas e interpretar as condições de assumir atitudes colaborativas para o bem comum. Por ser sui generis em sua existência, isto é, não necessitar de normas firmes (contrato) nem de bases documentais (teorias) para homologar a "ontologia" de suas responsabilidades, o mundo da vida é rico por ser uma base existencial pré-teórica, um estoque de sentidos inesgotável, a partir do qual é possível efetivar leituras de mundo e situar aprendizagens que renovam as estruturas evolutivas de suas instâncias de ação, concebidas como mecanismos do universo: cultura, sociedade e personalidade (HABERMAS, 2001).

Por se garantir como grandezas de referências, os componentes do MV orientam-se por um medium que estrutura a desenvoltura no interior de suas ações: a linguagem. Diferenciandose de acordo com as situações, a linguagem divide as atitudes (atos) de acordo com a intenção de suas próprias coordenações. Seus conteúdos enunciativos situam os sentidos sobre a realidade e a intervenção sobre suas próprias possibilidades de mudar. Em razão disso, Habermas (2004, p. 28) enfatiza que a linguagem "representa uma forma empiricamente universal de comunicação, para a qual não há alternativa em nenhuma das formas de vida conhecidas".

No que se refere ao mundo dos sistemas, Habermas (2001) o compreende como um complexo dialético que contrabalanceia a existência do mundo vivido. Sua desenvoltura existencial implica a dupla dimensão que baliza a teoria da sociedade habermasiana, suscitada pela forma de ser da sociedade moderna. No entanto, o mundo sistêmico só existe por causa do mundo vivido, com o qual mantém uma relação parasitária. A conduta de desenvoltura dos sistemas, amplamente exigente de uma auto independência alheia ao mundo vivido, gera uma necessidade de dinamizar e força o mundo vivido a desempenhar um papel que só é complementar, diante das dominâncias impostas pelo mundo sistêmico. Quando o quadro de coerções é suficiente para abalar o mundo vivido, as "vitórias" do mundo dos sistemas vão amontoando saldos positivos no êxito de seus interesses, profundamente descompromissados com a justeza das decisões coletivas, com a veracidade de valores que contemplam a igualdade e com a verdade dos discursos éticos.

Amplamente correspondente ao enquadramento da economia e da política nas esferas de ação social, a comunicação perde sua estrutura de ação, e a instrumentalização do entendimento sofre perdas, em decorrência da violência estrutural que se espalha como a linguagem comum: a violência simbólica, como dissimuladora e reprodutora do controle 
cultural/social, e a violência física, como escoadouro da incapacidade de manter com o outro uma relação de compatibilidade, de igualdade e de entendimento mútuo. Nessa dimensão sistêmica, a linguagem é reordenada como um veículo que cada vez mais perde sua condição de medium, através do qual as trocas simbólicas dos sentidos formam os significados interativos das verdades partilhadas em conjunto.

No mundo sistêmico, as atividades guiam-se estrategicamente rumo à obtenção de sucessos cumulativos, firmando seus imperativos (dinheiro e poder) como a linguagem da força simbólica sobre todas as dimensões do cotidiano, especificamente as práticas humanas em sociedade. Os imperativos sistêmicos são "deslinguistificados" porque mantêm como referência a funcionalidade da ideologia que os gerou e se autorreproduzem independentemente do bem comum, da discussão pública ou da participação integrada dos sujeitos falantes e ouvintes. O fortalecimento integrado dos imperativos sistêmicos não implica, necessariamente, a evolução social, cognitiva e cultural das sociedades, mas o aumento da capacidade de controlar as sociedades e seus problemas estruturais: corrupção, fome, miséria, drogas, analfabetismo, desemprego, consumismo, entre outras patologias sociais.

Dessa feita, as duas principais categorias criadas por Habermas (sistema e mundo vivido), para entender o (des)equilíbrio social, contribuem para que ele possa configurar uma nova leitura da modernidade e apontar os entraves que a tornaram "doente", isto é, em que sentido as patologias da modernidade fizeram-na esmorecer sob seus próprios fundamentos, impedindo-a de realizar-se em sua plenitude, considerando seus ideários originais. Assim, a resposta encontrada por Habermas $(2001 ; 1999 ; 2000)$ sobre o verdadeiro diagnóstico que traz patologias para a sociedade moderna é o que ele denomina de "colonização do mundo vivido", uma severa e profunda interferência sofrida pelo MV que, ao longo dos tempos, "contamina" cada vez mais o cotidiano, invade as plataformas de entendimento das coisas no mundo, na perspectiva de neutralizar a base de ação natural do sujeito, e imprime-lhe outra configuração comportamental.

Uma das hipóteses de Habermas (1980), fundada primeiramente em Marx, é de que a instrumentalização das formas tradicionais de vida promovidas pelo capitalismo é uma forma de tornar cada vez mais robusto o fenômeno do trabalho na vida moderna e de substituir os complexos processos da aprendizagem reflexiva (práxis) pelos facilitados, hábeis e eficientes mecanismos de ação da aprendizagem racionalizante (reificação/coisificação), fruto da automatização da economia e de seus impactos profundos no mundo vivido. Desse modo, Habermas (1980) vai além de Marx e acredita que o domínio dos subsistemas econômicos não 
se restringe a conduzir os eixos de ação que estão diretamente inter-relacionados aos seus domínios como, por exemplo, o trabalho, mas se esforça para estender a reificação à totalidade da vida humana, violando até mesmo as conquistas da modernidade. Habermas (1980) considera que a reificação expande a integração dos sistemas nas esferas da vida privada, em todas as dimensões arvoradas pela subjetividade. Matizando os sentimentos, as expressividades e a existência no mundo, a reificação interfere, drasticamente, no lócus essencial das interrelações, das inter-subjetivações, que dinamizam a construção de significados comuns em suas relações comunicativas: a reprodução do mundo vivido. Assim, Habermas (1980) pontua que a reificação não só estagna as relações do $e u$ diante dos contornos econômicos, como também dimensiona o levante da racionalidade instrumental na sociedade, como ambiência ideal às formas de ser e de pensar, propícios ao mundo sistêmico, dominando os espaços de ação favoráveis ao agir comunicativo. O dinheiro e o poder, na perspectiva habermasiana, são as "bactérias" mais fortes e resistentes do império sistêmico nas veias do mundo vivido. A colonização ocorre justamente quando essas forças concretas assumem cada vez mais relevância na vida privada e na pública e promovem a integração social (aderência à condução da ordem pré-estabelecida), desarticulando o agir comunicativo que promove a evolução social (progresso das experiências e das competências cognitivo-linguísticas).

A subsunção do mundo vivido, como esfera subserviente ao mundo sistêmico, agoniza a racionalização e a reprodução do MV (lógica do desenvolvimento), em detrimento do sucesso do MS (dinâmica do desenvolvimento). Nesse jogo diacrônico, a socialização da comunicação é, cada vez mais, substituída pela automação dos sentidos no cotidiano, a qual o torna cada vez mais legalista (direito), monetarizado (economia) e burocratizado (administração), o que agrava o quadro social das patologias da sociedade moderna.

A hipótese global que tudo isto se obtém para a análise dos processos de modernização é que o mundo da vida, progressivamente racionalizado, acaba desacoplado dos âmbitos de ação formalmente organizados e cada vez mais complexos que são a Economia e a administração estatal, ficando sob sua dependência. Esta dependência, que provém de uma mediatização do mundo da vida pelos imperativos sistêmicos, assume a forma patológica de uma colonização interna na medida em que os desequilíbrios críticos na reprodução material (isto é, as crises de controle analisáveis em termos de teoria dos sistemas) só podem evitar-se ao custo de perturbações simbólica do mundo da vida (ao custo de crises, pois, que 'subjetivamente' experimentam-se como ameaças à identidade ou de patologias) (HABERMAS, 2001, p. 432-3). 
Como as patologias sociais se processam por meio desse "caos" entre mundos (MS versus $\mathrm{MV}$ ), as explicações sobre suas causas correspondem aos interesses da economia sobre as formas de vida, desarticulando a modernidade cultural pela supremacia da modernização econômica. Por esse intermédio, a perda de sentido e a perda da liberdade fazem parte da atmosfera sufocada do mundo vivido, quando passa a desarticular sua complexidade intrínseca às desestruturações provocadas pelas estratégicas dos sistemas. Os valores éticos, morais e estéticos, compartilhados pela experiência, pela sociabilidade e pela expressividade, são alvos diretos da indústria da cultura e substituídos pelo hiperindividualismo, pelo egocentrismo e pelo consumismo. Essas investidas dinâmicas tornam tudo mediatizado por valores produzidos pelo sistema, reproduzidos pela família, pela escola e pelas mídias, profundamente introjetados nas estruturas subjetivas. Nesse sentido, a dinâmica do desenvolvimento controla as referências e condiciona as vertentes das relações sociais amplamente carentes de conteúdos significativos para promover a interação necessária ao agir comunicativo.

A intromissão das forças externas do mundo sistêmico nas estruturas internas do mundo vivido causa ainda mais preocupação, segundo Habermas (2001), quando perturba a ordem estrutural das três esferas de reprodução do mundo vivido: a) a cultura: por impedir que a transmissão cultural transcorra espontaneamente entre as gerações e corroa a base natural de valores comuns que os sujeitos levam para a escola; b) a sociedade: por minimizar o sentido de evolução social, correlacionando-o apenas às integrações dos sujeitos às normalizações estabelecidas como referências legítimas para o funcionamento dos papéis sociais e dificultando as relações intersubjetivas de sujeitos educativos; c) a personalidade: por dificultar a interação comunicativa entre as subjetividades e a socialização de sentidos comuns ao desenvolvimento cognitivo. Cada vez mais procedimentais em sua forma de interferir no cotidiano da vida, por meio das relações de posse, de valor, de consumo e de formalismos (interação comprometida) entre agentes sociais e instituições, a monetarização e a burocratização vão se enfincando nas estruturas sociais e versatilizando-se como respostas para as crises e os problemas econômicos (principalmente relacionados ao trabalho) e administrativos (voltados para redefinir a opinião pública coletiva).

Reduzir a compreensão e a participação política é uma maneira de firmar atitudes instrumentais sobre o dever ético e de marcar a indiferença e o descompromisso com o outro, características sobrepostas à intersubjetividade e ao respeito mútuo. As consequências da colonização são profundas na cultura, na subjetividade e na sociedade e fazem com que o thelos da linguagem perca as referências de mediação do entendimento mútuo e assuma uma máscara 
própria à coordenação de interesses finais. Até esferas de discursos elaborados, como, por exemplo, a ciência, tornam-se vulneráveis, penetradas por motivos alheios aos sentidos das descobertas, como fator de colaboração para o bem comum. Nesse processo castrador, a característica enriquecedora da linguagem, potencializada pelas vias do entendimento possível, cada vez mais se destitui de suas forças naturais e absorve predomínios de obtenção de sucessos em negociatas que não se preocupam com o entendimento, mas com o rendimento da ação particularizada. Isso implica dizer que o saber inquirido pelo sistema é castrado desde sua base natural, situado no mundo vivido e contaminado desde suas formas originais, pré-científicas, até a construção metódica do conhecimento na Ciência. A sofisticação da linguagem científica, hiperelaborada, dirigida a fins específicos, reduz o potencial da comunicação a mero objeto procedimental. A desenvoltura do conhecimento cada vez mais especializado guarda a própria ideologia que gerou sua linguagem, sua aplicação e seu valor, adequados para o modo de pensar sistêmico.

Nesse aspecto, a escola dificilmente livra-se do domínio das invasões sistêmicas, externas à sua conduta. A escola colonizada transforma o saber em conhecimento funcional, referência unidimensional da Ciência baseada na ideologia do poder prático. As variáveis que sustentam tal ideologia são regidas pela dinâmica do desenvolvimento econômico e dirigemse às metas de manutenção e de maximização do poder produtivo, ao aumento no consumo, à ideia de estabilidade, ao bem-estar e à felicidade. O sucesso da produção depende dos esforços da escola em designar currículos mediadores da inter-relação entre técnica e ciência como a ideologia da aprendizagem ideal (HABERMAS, 1997), como a fase áurea do desenvolvimento humano. A escola passa a coordenar aprendizagens sob a profetização da própria ideologia dos sistemas e dissemina a sensação de integrar o indivíduo "reduzido" como progresso do sujeito "universal". Em outras palavras, a escola passa a confundir interesses sociais com interesses sistêmicos e, detida em suas formas de socializar o saber, mantém as formas de manipular o conhecimento, absorvendo e, ao mesmo tempo, induzindo ao empobrecimento das formas naturais de vida e às desestruturações da própria vida em sociedade: a cultura da fugacidade, do acúmulo de informações desconexas e da fragilidade de valores, como as crises da identidade coletiva, o individualismo e o enfraquecimento da solidariedade e o crescente enfraquecimento cultural, exemplos de patologias que afligem o mundo da vida. Praticamente desprovida de recursos para lidar com diásporas como essas, a escola tende a se abster quando, ao contrário, muitas vezes reforça esses mesmos dilemas. É desse modo que a racionalidade 
comunicativa se encurta e transpõe-se para manifestações que minimizam a dimensão transformadora da educação.

Do ponto de vista empírico, um leque de circunstâncias ampara e, ao mesmo tempo, dá forças à colonização escolar que, da educação infantil à universidade, povoa as relações com o conhecimento e imprime-lhe aspectos de manipulação. A colonização firma-se na escola como um processo "normal", que se revigora: a) por meio dos expedientes funcionais dos agentes administrativos que garantem a ordem dos papéis burocráticos; b) do planejamento do ensino, que garante as didáticas e as metodologias específicas da pedagogia tecnicista; c) das relações mais normativas do que comunicativas entre professores e alunos; d) da consequente reprodução do saber e da cultura; e) da indução de valor do conhecimento válido (prático) como conhecimento útil, entre outros aspectos.

Invadida pelas leis do mercado (economia), pelos germes das negociações (monetarização) e pelas gerências políticas (condução normativa), a escola tem suas relações cotidianas com aprendizagens constrangidas pelas dimensões do dinheiro e do poder. A invasão do sistema condutor atinge seu auge quando se torna cada vez mais comum e amplamente naturalizado no ambiente da formação humana na escola. Em síntese, os benefícios que a colonização do MV traz para o MS são promoventes da inércia, do comodismo, do favorecimento dão ao Estado mais poder em sua governança política e econômica, livrando-o de pressões e reivindicações por parte de possíveis insurgentes. A ideia de desenvolvimento, como matriz funcional do fortalecimento dos sistemas, é confundida com o desenvolvimento da competência individual, e isso torna o sujeito muito mais um agente reprodutor das diretrizes normativas da cultura invadida do que um agente do agir comunicativo. A essa conduta integradora da ordem sistêmica, a partir dos domínios econômicos, amplamente inibidor da reprodução racional do mundo vivido, Habermas (1980) chamou de dinâmica do desenvolvimento, cuja racionalidade instrumental se planifica nas veredas das dominações impostas pelo MS sobre o MV, sufoca as perspectivas emancipatórias da aprendizagem refletiva e desvela uma espécie de "razão invertida" para a educação.

\section{CONSIDERAÇÕES FINAIS}

Na base de ação do tecnicismo na educação, a sociedade de mercado é a principal referência do planejamento curricular, que prioriza a profissionalização como o "peso e as medidas" da formação adequada para a competitividade e, praticamente, é um dos valores mais 
importantes da educação contemporânea. A base de validade do sistema de ensino é avaliada pela eficiência com que a educação põe em marcha a obtenção de resultados concretos para a economia de mercado, com a formação pautada na capacidade de reproduzir o controle técnico.

Um dos germes mais potencializados que invade os espaços libertários dos processos educativos é a valorização da técnica como elemento ideológico na educação. Esse fator preocupante para a educação emancipatória, atrelado aos vieses das contradições educacionais da modernidade, serve como instrumento de sustentação de domínios que colonizam o potencial emancipatório da educação por lhe imprimir um caminho estreito a ser seguido. Toda ação "desviante" de processos educativos que, em primeiro plano, não sirvam para fins práticos para o mercado de trabalho parece ser algo que não merece atenção por parte dos sistemas integradores da Economia. Em que pese tudo isso, os investimentos na educação fizeram do tecnicismo a manifestação mais singular da razão instrumental. A razão técnica coloca-se insistentemente nas políticas públicas, nas propostas de ensino, no discurso mais retórico da gestão escolar, no paradigma indispensável à formação de professores e no método mais eficiente para "reter" o conhecimento.

Assim, considerando o exposto, é possível afirmar que os processos educativos conduzidos pelo tecnicismo parecem não privilegiar o exercício de uma prática legitimadora da comunicação e estreitam o discurso para não priorizar a argumentação. Essa contextura, de acordo com Habermas (2001; 1999), afasta cada vez mais as propostas originais da modernidade para a educação e crava no inconsciente coletivo a negação das utopias universais defendidas pelo projeto moderno de mundo, voltadas para a aprendizagem e para a vivência de princípios humanos comuns. Por essas vias, vimos que as condições do racionalismo aplicado materializam estruturas que entrelaçam a educação e a ordem do mundo prático. As materializações da racionalidade cognitivo-instrumental, prático-moral e prático-estética não são frutos de processos de aprendizagem, isto é, de processos evolutivos, mas sofrem as adaptações das circunstâncias externas, sobretudo promovidas por reforços contrários à lógica do desenvolvimento e à educação em estágio de emancipação. A fase aguda desse jogo de forças, que enquadra a liberdade do saber não mais como transcendência, mas como adaptação, coaduna-se com a ciência e com a técnica como o principal dueto da fase moderna do capitalismo avançado, faz da educação a ponte intermediadora dos sistemas ligada aos desdobramentos em que a formação humana se enquadra e caracteriza-se como um subsistema de condução e domínio social. Esse quadro de desajustes se coloca para a educação como uma 
denúncia sem precedentes, já que ela é um dos principais fundamentos do projeto da modernidade.

Habermas (2001) assevera que o desacoplamento entre os mundos sistêmicos/vividos é uma questão moral, porque, quanto mais transpusermos o mentalismo que estreita nossa relação com os saberes e com o mundo e atingirmos estágios cognitivos que facilitem a desenvoltura da linguagem e o papel social do agente comunicativo, mais estaremos facilitando a abertura de janelas alternativas que podem nos mostrar paisagens muito além da racionalidade instrumental. Dessa feita, a abertura de outras janelas cognitivas nos mostra que a educação não é um palco de somente uma cena nem está imbuída somente de contornos estratégicos, como laços condutivos que manobram suas ações guiadas em detrimento do despertar da autonomia. Tampouco a ideologia da técnica conduz a ciência como ideologia em sua totalidade. Nesse sentido, a tentativa de abrir janelas entre a educação e a racionalidade instaura uma nova ordem para o cotidiano da escola e, ao mesmo tempo, joga luzes na compreensão para que percebamos as ambivalências da razão e entendamos como sua face instrumental rouba de nós mesmos a capacidade de acreditar nas utopias possíveis.

\section{REFERENCIAS}

GOODSON, Ivor. F. Currículo: teoria e história. 6. ed. Petrópolis: Vozes, 2003.

HABERMAS, Jürgen. Verdade e justificação: ensaios filosóficos. São Paulo: Loyola, 2004.

HABERMAS, Jürgen. Consciência moral e agir comunicativo. Rio de Janeiro: Tempo Brasileiro, 2003.

HABERMAS, Jürgen. Teoria de la acción comunicativa: crítica de la razón funcionalista. Madrid: Taurus, 2001, v 2.

HABERMAS, Jürgen. O discurso filosófico da modernidade. Lisboa: Dom Quixote, 2000.

HABERMAS, Jürgen. Teoria de la acción comunicativa: racionalidad de la acción y racionalización social. Madrid: Taurus, 1999, v. 1.

HABERMAS, Jürgen. Técnica e ciência como ideologia. Lisboa: Edições 70, 1997.

HABERMAS, Jürgen. Pensamento pós-metafísico. Rio de Janeiro: Tempo Brasileiro, 1990.

HABERMAS, Jürgen. A crise de legitimação no capitalismo tardio. Rio de Janeiro: Tempo Brasileiro, 1980. 
? INOVAÇÃo

LUCKESI, Cipriano Carlos. Filosofia da educação. São Paulo: Cortez, 1994.

SAVIANI, Dermeval. Las teorias de la educación y el problema de la marginalidad en América Latina. Revista Argentina de Educación. Buenos Ayres, n 02, 1983.

SHULTZ, Theodore W. O capital humano: investimento em educação e pesquisa. Rio de Janeiro: Zahar Editores, 1973.

SHULTZ, Theodore W. O valor econômico da educação. Rio de Janeiro: Zahar Editores, 1967.

WEBER, Max. A ética protestante e o espírito do capitalismo. São Paulo: Martin Claret, 2001.

WEBER, Max. Economia e sociedade: fundamentos da sociologia compreensiva. 3. ed. Brasília: UnB, 2000, v. 1. 


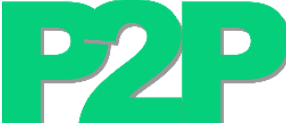

? INOVAÇão

28

P2P \& INOVAÇÃO, Rio de Janeiro, v. 4 n. 2, p. 6-28, Mar./ Ago. 2018. 